\title{
A MODIFIED MODEL OF RESIDUAL STRENGTH PREDICTION FOR METAL PLATES WITH THROUGH-THICKNESS CRACKS
}

\author{
Yanping Li, Jianjun Wang, Weiguo Guo, Jin Guo \\ Northwestern Polytechnical University, School of Aeronautics, Xi'an, China \\ e-mail: jianjunw87@126.com; weiguo@nwpu.edu.cn
}

\begin{abstract}
A new model, accurate and easy-to-apply, has been proposed to predict the residual strength for metal plates intact or with different damage degrees. In this model, we introduced the damage degree factor (DDF) to quantify the initial damage condition of a plate. The middle crack tension $(\mathrm{M}(\mathrm{T})$ ) tests and multiple site damage (MSD) tension tests were performed on plate specimens in aluminum alloy LY12-CZ and 2524-T3, respectively. For various damage degrees, the predicted results of this new model showed an improved correlation with test results compared to the net section yield criterion, $K$-apparent criterion and Duong's method.
\end{abstract}

Keywords: residual strength, damage degree factor, crack, multiple site damage

\section{Introduction}

The strength of a structure can be significantly degraded by the presence of cracks. During the whole lifetime, structures may suffer from many kinds of damage, especially cracks, which will reduce their loading capacity and even collapse the whole structure. The damage tolerance design, therefore, is widely used in aerospace industry to manage the crack propagation through the application of fracture mechanics (Riddick, 1984). The load or force that a damaged object or material can still withstand without failing is called the residual strength, which is related to material toughness, fracture size, geometry and orientation. To find an effective method to predict residual strength is an approach to prevent materials and structures from catastrophes caused by damage.

Since Griffith proposed the concept of energy release rate based on energy balance and established one of the basic equations in 1921 - Griffith criterion (Griffith, 1921), fracture mechanics was established as a branch of solid mechanics. In a subsequent study, Irwin (1948) partitioned the energy into two categories: the elastic stain energy and the dissipated energy (surface energy and plastic dissipation). He gave a modified version of Griffith's energy criterion and made it applicable to deal with the fracture of ductile materials. Later in 1957, Irwin further proposed to use the stress intensity factor to represent the stress singularity at the crack tip, thus the phenomenon of low stress brittle fracture was successfully explained. Then, a number of methods to predict residual strength of cracked structures were proposed. For example, fracture toughness criteria, including various crack driving force parameters, such as the elastic energy release rate $G$, the stress intensity factor $K$, the J-integral, the crack-tip opening displacement (CTOD) and the crack-tip opening angle (CTOA), etc. were examined (Irwin, 1957; Zhu, 2011; Zhu and Joyce, 2012). Besides, in engineering applications, we have the net section yield criterion (Cherry et al., 1997), Feddersen's engineering method (Feddersen, 1971), finite element method (Li and Siegmund, 2002; Scheider and Brocks, 2008; Zerbst et al., 2009). Moreover, some other criteria including the ligament yield criterion (Jeong and Brewer, 1995; Swift, 1993), average 
displacement criterion (Jeong and Brewer, 1995) and average stress criterion (Jeong and Brewer, 1995; Young et al., 1998) were developed.

Guz and Dyshel (2004) investigated the effect of mechanical properties of plates, geometrical parameters of plates and cracks on predicting the critical stresses (residual stresses) corresponding to local loss of stability of plates with the crack in tension. They also introduced an equation to predict the critical stress for plates with straight and curved cracks by empirical results obtained by means of mechanical and geometrical parameters of plates and cracks. Duong et al. (2001) proposed an energy-based method for predicting the strength of MSD plates. Based on the suggestions of Broberg (1971) and Cotterell and Reddel (1977), the total work of fracture can be expressed by the essential work performed in the end region and the non-essential work in the screening plastic region. Through the established failure line, the predicted values can be obtained by forcing the crack link-up to occur only at the load level which yields the parameters satisfying the equation of failure line.

Several institutions, including the Federal Aviation Administration (FAA), the National Aeronautics and Space Administration (NASA), sponsored programs that developed and assessed methodologies and fracture criteria suitable for predicting the residual strength of structural elements with MSD. Most of the criteria mentioned above are presented in the list. Therein, CTOA and the ligament yield criterion are widely used because of their simplicity of application and extensive correlation with test data for both simple laboratory specimens and complex structures, i.e. stiffened and splice plates (Wang et al., 1996; Newman et al., 1993; Young et al., 1998). Most of these classical criteria are established on the basis of elastic-plastic fracture parameters for a single middle crack. While these criteria extended to intact plates and MSD plates, their predictability are yet to be confirmed. Guz's method (Guz and Dyshel, 2004) and Duong's method (Duong et al., 2001) are good in predicting the residual strength of plates with single straight or curved cracks and MSD, respectively. However, the process of determining the proportionality factor for the former and establishing the failure lines and link-up load curves for the latter is relatively complicated. In general, there is still a potential improvement in applicability and accuracy of current methods. Thus, a universal model, which is available for various damage conditions (i.e. intact, with single middle crack or with MSD) and easy-to-apply, is expected to be built up.

\section{Damage degree factor model}

\subsection{Damage degree factor}

Considering through-thickness mode I crack of length $2 a$ in an infinite plate, shown in Fig. 1, the plate is subjected to a biaxial stress $\sigma$ at infinity. The general form of stress can be simplified by a tensor representation (Paris and Sih, 1965; Liu et al., 2015) as

$$
\sigma_{i j}=\frac{K_{I}}{\sqrt{2 \pi r}} f_{i j}(\theta)
$$

where $\sigma_{i j}$ are the Cauchy stresses, representing the stress $\sigma_{x}, \sigma_{y}$ and $\tau_{x y} ; K_{I}$ is the stress intensity factor, the subscript $I$ stands for mode I crack; $r$ is the distance from the crack tip; $\theta$ is the angle with respect to the plane of the crack; $f_{i j}(\theta)$ is the function that depends on the crack geometry and loading conditions. It is constant in an infinite plate.

In mode I crack growth direction $(\theta=0), f(\theta)=1$. The intensity factor $K_{I}$ could be expressed as $K_{I}=\sigma \sqrt{\pi a}$. The stress in the crack propagation direction is

$$
\sigma_{y}=\frac{K_{I}}{\sqrt{2 \pi r}} \quad \theta=0
$$




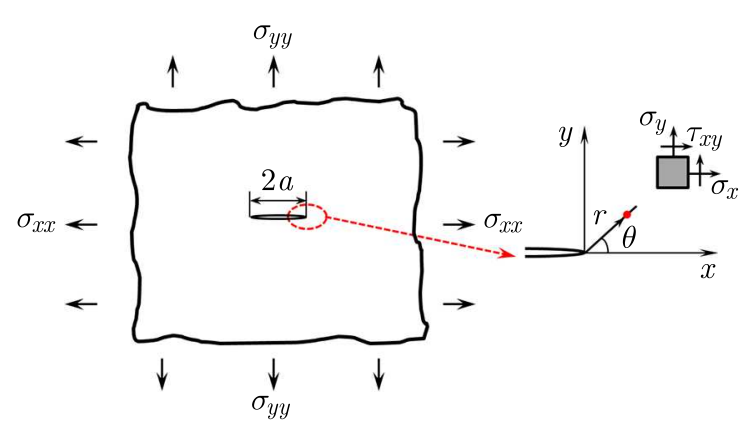

Fig. 1. Mode I crack in an infinite plate

In general, the stress field at the crack tip is determinate when the stress intensity factor $K_{I}$ is known. Eq. (2.2) gives an elastic solution which could be infinite at the crack tip. However, in most engineering materials, the region around the crack tips reaches the yield stress of the material and the plastic zone is surrounded by the elastic zone. On the assumption of small scale yielding, while the plastic zone is small enough, the stress intensity factor $K_{I}$ is still likely to determine the stress field around the plastic zone. The linear elastic theory could still be used to estimate the size of the plastic zone (Broek, 2012). In front of the crack, we can obtain

$$
r_{p}=\frac{1}{2 \pi}\left(\frac{K_{I}}{\sigma_{y s}}\right)^{2}
$$

where $r_{p}$ indicates the size of the plastic zone at the crack tip (McClintock and Irwin, 1965). We suppose that the stress intensity factor $K_{I}$ reaches its critical value $K_{C}$, when the normal stress $\sigma_{y}$ reaches the ultimate tensile stress (UTS) $\sigma_{b}$. The plastic zone also increases to its critical size, so that the crack grows and the material behind the crack tip unloads. We define the size of the corresponding critical plastic zone as $R_{p}$, which is illustrated in Fig. 2. $R_{p}$ can be derived from the formula of the critical state $\sigma_{b}=K_{C} / \sqrt{2 \pi r}$, that is

$$
R_{p}=\frac{1}{2 \pi}\left(\frac{K_{C}}{\sigma_{b}}\right)^{2}
$$

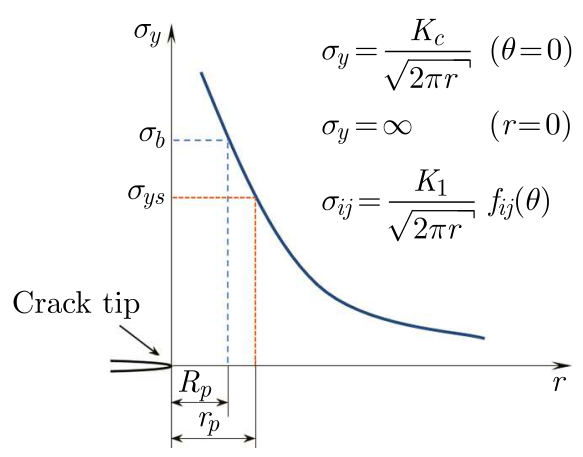

Fig. 2. Normal stress at the crack tip and illustration of $r_{p}$ and $R_{p}$

As a reflection of material properties, $R_{p}$ can be used as a parameter to measure the damage tolerance of the material: the ratio of toughness to strength. Because of the plastic deformation at the crack tips, the effective crack size would be larger than the linear solution (Irwin, 1960). The length of the equivalent crack could be expressed as $2\left(a+R_{p}\right)$. For an intact plate, $2 a \rightarrow 0$, it could be regarded as an equivalent crack of $2 R_{p}$ long when it is loaded. Thus, $R_{p}$ can be used to evaluate the damage resistance of materials. Here is a new definition

$$
\xi=\frac{a}{R_{p}}
$$


where $\xi$ denotes the DDF, as Eq. (2.5) shows. It is defined as the ratio between the half-length of crack $a$ and $R_{p}$, and used for describing the damage conditions of plates. The geometrical parameters of plates and cracks, as well as the mechanical properties of materials are taken into account in the DDF model. In terms of $\xi$, the damage degree of a plate is known.

\subsection{Residual strength reduction coefficient}

By dint of the concept of damage variable of Kachanov (1958) and Lemaitre (1985), we can illustrate the expression of the residual strength reduction coefficient $\Delta$ by way of analogy. For a damaged element at microscale, its damage variable can be expressed by the ratio of the damage area and the overall section area. And the effective stress is concerned with the effective resisting area. Considering the microstress concentrations in the vicinity of discontinuities and the interactions between closed defects, the effective resisting area will not strictly be equal to the difference between the overall section area and the damaged area. Similarly, at macroscale, strength of the plate is not proportionate to the effective resisting area. Through experimental research, Moukawsher et al. (1996) pointed out that both the net section yield criterion and $K$-apparent criterion always overestimate the residual strength in certain conditions as they do not consider the structural load carrying capacity loss caused by plastic deformation at the crack tip. Therefore, a modified coefficient should be worked out.

We set $S$ as the overall cross-section area of the plate, $S_{D}$ as the damaged area. $\sigma_{C}$ indicates the residual strength obtained by calculation, and $\Delta(\xi)$ represents the residual strength reduction coefficient. Then we have

$$
\frac{\sigma_{C}}{\sigma_{b}}=\frac{S-S_{D}}{S} \Delta(\xi)
$$

In terms of the analysis on a series of DDFs corresponding to each critical ultimate strength (Li et al., 2003), and considering the boundary conditions:

- when $\xi \rightarrow 0, \Delta(\xi)=\Delta(0)=1$, the plate is intact, failure can be controlled by the UTS;

— when $\xi \rightarrow \infty, \Delta(\xi)=\Delta(\infty)=0$, the plate completely loses its load carrying capacity.

The empirical function of the residual strength reduction coefficient for the though-thickness cracked plates could be given as

$$
\Delta(\xi)=\mathrm{e}^{-a \xi^{b}}
$$

where $a, b$ are defined as the material constants, given by experimental data.

\subsection{Damage degree factor model}

According to Eq. (2.6), Eq. (2.8) could be obtained via a simple mathematical formulation

$$
\sigma_{C}=\sigma_{b} \frac{S-S_{D}}{S} \Delta(\xi) \stackrel{\text { def }}{=} \sigma_{\xi}
$$

where $\sigma_{\xi}$ is defined as the residual strength obtained via DDF model. For the material selected, the value of the critical fracture toughness $K_{C}$ and the critical crack tip stress $\sigma_{b}$, which are bound up with the material properties, can be determined. Therefore, the residual strength of a certain plate can be easily obtained through Eq. (2.8). Notice here, $K_{C}$ should be obtained by experiments or empirical equations (Zerbst et al., 2009). The value of $K_{C}$ is affected by thickness and width of the specimens (Yablonskii, 1980), its value has a great impact on the accuracy of the DDF model prediction. 
Here is a new failure criterion, expressed as

$$
\sigma \leqslant \sigma_{b} \frac{S-S_{D}}{S}
$$

where $\sigma$ represents the load applied on the plate. If $\sigma$ satisfies inequality (2.9), the plate is secure. Otherwise, it will be damaged.

We introduce $[\sigma]$ as the stress from the maximum-normal-stress theory (Budynas and Nisbett, 2008), $n$ as the safety factor. Then we have $\sigma \leqslant[\sigma]=\sigma_{b} / n$, the safety factor can be obtained by

$$
n=\left(\Delta(\xi) \frac{S-S_{D}}{S}\right)^{-1}
$$

\section{Empirical analysis of the damage degree factor model}

In this Section, middle crack tension tests and MSD tension tests were carried out to validate the DDF model. We take an aluminum flat plate for example as it is commonly used in aircraft industry. Table 1 lists 3 models, including the net section yield criterion, $K$-apparent criterion and the DDF model. The net section yield criterion, using yield stress and the ratio of net and gross cross-sectional areas as variables, predicts the residual strength by material properties and geometrical dimensions (Cherry et al., 1997). In the fracture toughness $K$ criterion, $\sigma$ is determined by the material properties. And the rest part $\sqrt{\pi a \sec (\pi a / W)}$ is relevant to geometrical dimensions (Kirsch, 1989). These two yield criteria are commonly used in calculating the residual strength. In order to further improve the prediction accuracy, besides the factors relevant to material properties and dimensions, the DDF model also introduces the residual strength reduction coefficient, which is a term related to plastic deformation.

Table 1. The prediction models of residual strength

\begin{tabular}{|c|c|c|}
\hline Symbol & Model & Formula \\
\hline \hline$\sigma_{N}$ & Net section yield criterion (Cherry et al., 1997) & $\sigma_{N}=\sigma_{y s} \frac{S-S_{D}}{S}$ \\
\hline$\sigma_{K}$ & $K$-apparent criterion (Kirsch, 1989) & $\sigma_{K}=K / \sqrt{\pi a \sec \frac{\pi a}{W}}$ \\
\hline$\sigma_{\xi}$ & DDF model & $\sigma_{\xi}=\sigma_{b} \frac{S-S_{D}}{S} \Delta(\xi)$ \\
\hline
\end{tabular}

\subsection{Middle crack tension tests}

The $\mathrm{M}(\mathrm{T})$ specimens were made of aluminum alloy LY12-CZ, $6 \mathrm{~mm}$ thick. Figure 3 illustrates geometry of the specimens. The necessary mechanical parameters could be obtained by experiments, shown in Table 2 ( $\mathrm{Li}$ et al., 2003). The test results were obtained from experiments on 27 pieces of the $\mathrm{M}(\mathrm{T})$ specimens. Thus, the material constants $a$ and $b$ can be determined. The function of the residual strength reduction coefficient can be expressed as $\Delta(\xi)=\exp \left(-0.27 \xi^{0.27}\right)$.

Table 2. The mechanical parameters of $\mathrm{M}(\mathrm{T})$ specimens in $\mathrm{LY} 12-\mathrm{CZ}$

\begin{tabular}{|c|c|c|c|}
\hline$\sigma_{y s}[\mathrm{MPa}]$ & $\sigma_{b}[\mathrm{MPa}]$ & $K_{C}[\mathrm{MPa} \sqrt{\mathrm{m}}]$ & $K_{\text {app }}[\mathrm{MPa} \sqrt{\mathrm{m}}]$ \\
\hline \hline 323.4 & 450.8 & 93 & 73.2 \\
\hline
\end{tabular}

Table 3 presents the test results of the 3 different criteria. And in Fig. 4a, the scatter diagram which reflects their predictive abilities by the offset degree deviating from the $45^{\circ}$ reference line was built up. In this figure, the perfect agreement would be for all points to fall in the $45^{\circ}$ line. 


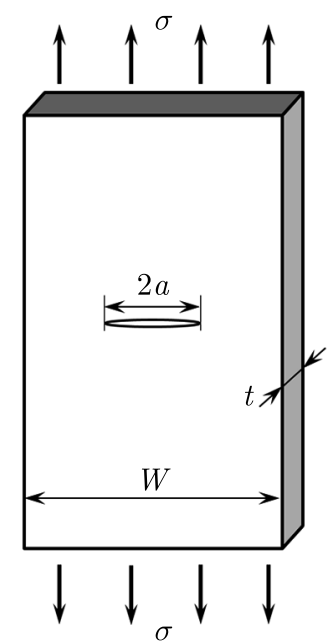

Fig. 3. Geometry of $\mathrm{M}(\mathrm{T})$ specimen

Table 3. Results of the middle crack tension test and 3 prediction models

\begin{tabular}{|c|c|c|c|c|}
\hline \multirow{2}{*}{$\begin{array}{c}\text { Relative } \\
\text { crack length } \\
2 a / W\end{array}$} & \multicolumn{3}{|c|}{ Prediction models } & Test \\
\cline { 2 - 4 } & $\begin{array}{c}\sigma_{N} \\
{[\mathrm{MPa}]}\end{array}$ & $\begin{array}{c}\sigma_{K} \\
{[\mathrm{MPa}]}\end{array}$ & $\begin{array}{c}\sigma_{\xi} \\
{[\mathrm{MPa}]}\end{array}$ & $\begin{array}{c}\text { average } \\
{[\mathrm{MPa}]}\end{array}$ \\
\hline \hline 0.000 & 323.4 & - & 450.8 & 466.2 \\
\hline 0.100 & 291.1 & 818.4 & 290.3 & 287.9 \\
\hline 0.118 & 285.2 & 561.9 & 294.7 & 291.1 \\
\hline 0.124 & 283.3 & 409.6 & 321.4 & 314.5 \\
\hline 0.150 & 274.9 & 332.6 & 274.2 & 271.8 \\
\hline 0.233 & 248.1 & 203.9 & 226.9 & 223.2 \\
\hline 0.248 & 243.2 & 335.2 & 264.3 & 269.4 \\
\hline 0.350 & 210.2 & 213.4 & 192.4 & 194.5 \\
\hline 0.500 & 161.7 & 126.9 & 134.4 & 132.1 \\
\hline
\end{tabular}

(a)

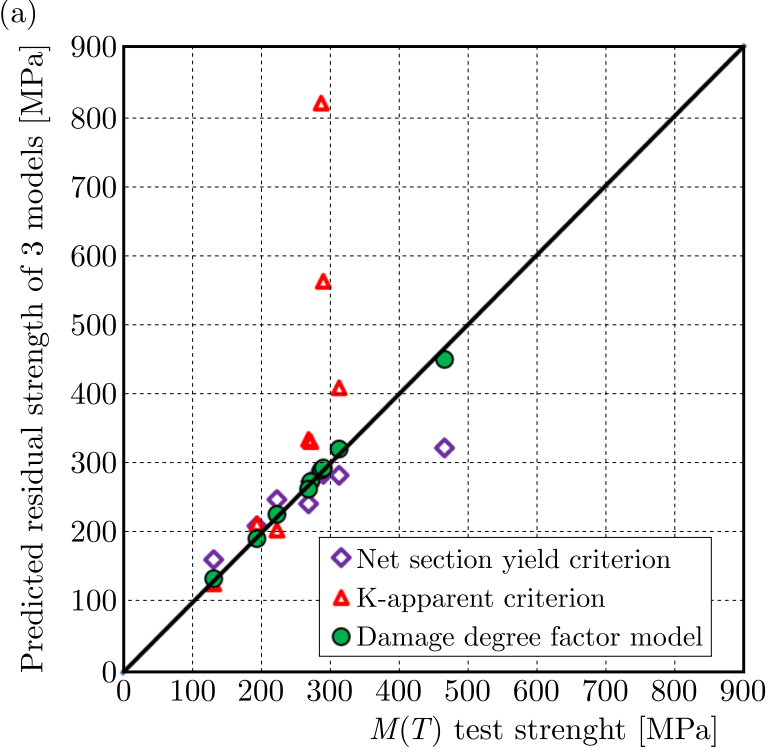

(b)

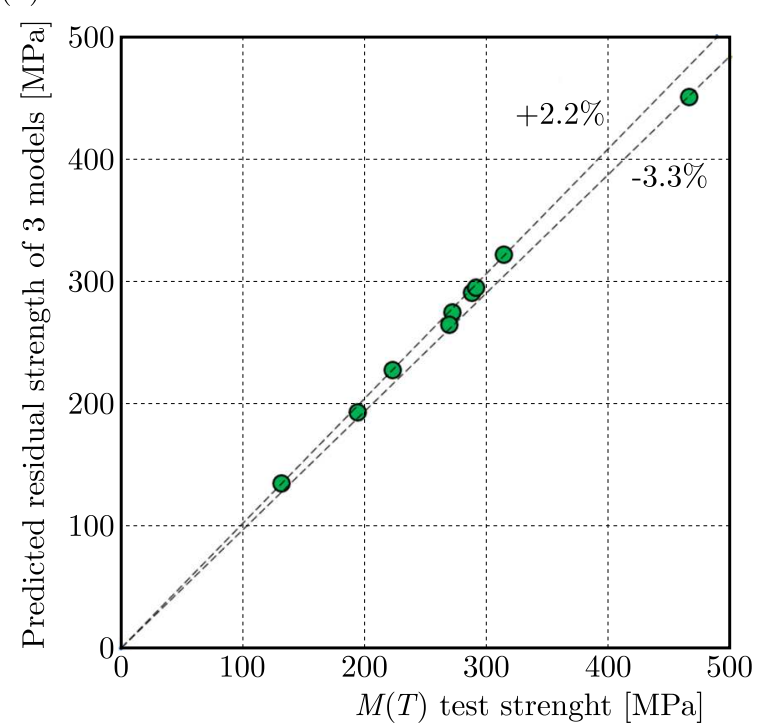

Fig. 4. (a) Empirical analysis results compared to other models of middle crack tension tests.

(b) Predictions of DDF model vs. test results of middle crack tension tests 
Comparing with the test results, it is obvious that the fracture toughness $K$-apparent criterion predictions overestimate the strength of plates. The $K$-apparent criterion is relatively accurate in predicting the failure strengths in a condition of relatively low strengths, while it meets relative large deviations with small relative crack length $2 a / W$. Based on the theory of linear elastic analysis, the $K$-apparent criterion does not take account of the loss of load capacity caused by plastic deformation at the crack tip (Cherry et al., 1997). It only applies to predicting the residual strength of the plates with relative high $2 a / W$. The net section yield criterion gives acceptable results when the relative crack length $2 a / W$ is relative large. But for intact plates $(a=0)$, there is a relative big deviation. Theoretically, the calculated residual strength for an intact plate should be equal to its UTS. It can be observed here, for the intact plate $(2 a / W=0)$, the predicted result of the DDF model corresponds closely to the theoretical one, with an error of $3.3 \%$.

As shown in Table 4, the maximum error and average error of the DDF model are only $-3.3 \%$ and $1.6 \%$, respectively, significantly less than that of the $K$-apparent criterion and the net section yield criterion. The DDF model is the most accurate among the 3 criteria. Figure $4 \mathrm{~b}$ shows the agreement between the DDF model predicted results and the middle crack tension tests results. The agreement between its predicted results and the test results is within $3.3 \%$.

Table 4. Maximum error and average error between prediction models and middle cracked tension test results

\begin{tabular}{|l|c|c|}
\hline \multicolumn{1}{|c|}{ Prediction model } & Maximum error [\%] & Average error [\%] \\
\hline \hline Net section yield criterion & -30.6 & 10.7 \\
\hline$K$-apparent criterion & +184 & 41.8 \\
\hline DDF model & -3.3 & 1.6 \\
\hline
\end{tabular}

\subsection{Multiple site damage tests}

The MSD tension tests were implemented on 15 unstiffened plates made of aluminum alloy 2524-T3, of $1.6 \mathrm{~mm}$ thick. These plates consisted of a central lead crack connecting several holes and small radial cracks emanating from the other holes. A schematic diagram of MSD specimens is shown in Fig. 5. The mechanical parameters of MSD specimens are listed in Table 5.

Table 5. The mechanical parameters of MSD specimens in 2524-T3

\begin{tabular}{|c|c|c|c|}
\hline$\sigma_{y s}[\mathrm{MPa}]$ & $\sigma_{b}[\mathrm{MPa}]$ & $K_{C}[\mathrm{MPa} \sqrt{\mathrm{m}}]$ & $K_{a p p}[\mathrm{MPa} \sqrt{\mathrm{m}}]$ \\
\hline \hline 318.13 & 449.55 & 163.29 & 104.91 \\
\hline
\end{tabular}

Similarly, the function of the residual strength reduction coefficient for 2524-T3 aluminum plate, $1.6 \mathrm{~mm}$ thick, (Fan et al., 2015) can be expressed as $\Delta(\xi)=\exp \left(-0.3 \xi^{0.24}\right)$.

As the central lead crack is longer than the other cracks, its stress intensity factor is the maximum. We take the central lead crack as the equivalent crack. That is to say, the half-length of the crack $a$ in Eq. (2.5) equals to the half-length of central lead crack $a_{2}$ in Fig. 5. The other cracks will be considered along with the residual cross sectional area.

For specimen No. 1 and No. 2, the three cracks $a_{1}, a_{2}, a_{3}$ connect together as the leading cracks. For specimen No. 11 and No. 14, $a_{1}$ and $a_{2}, a_{2}$ and $a_{3}$, connect as the leading crack, respectively. The diameters of the side holes, $a_{0}$ and $a_{4}$ are $6 \mathrm{~mm}$.

We listed the predicted results by the net section yield criterion, $K$-apparent criterion and by DDF model in Table 6, and the schema of test results and predicted results are shown in Fig. 6a. The results obtained by the net section criterion and the DDF model, show the same trend with the test results. The net section yield criterion gives conservative predicted values. 


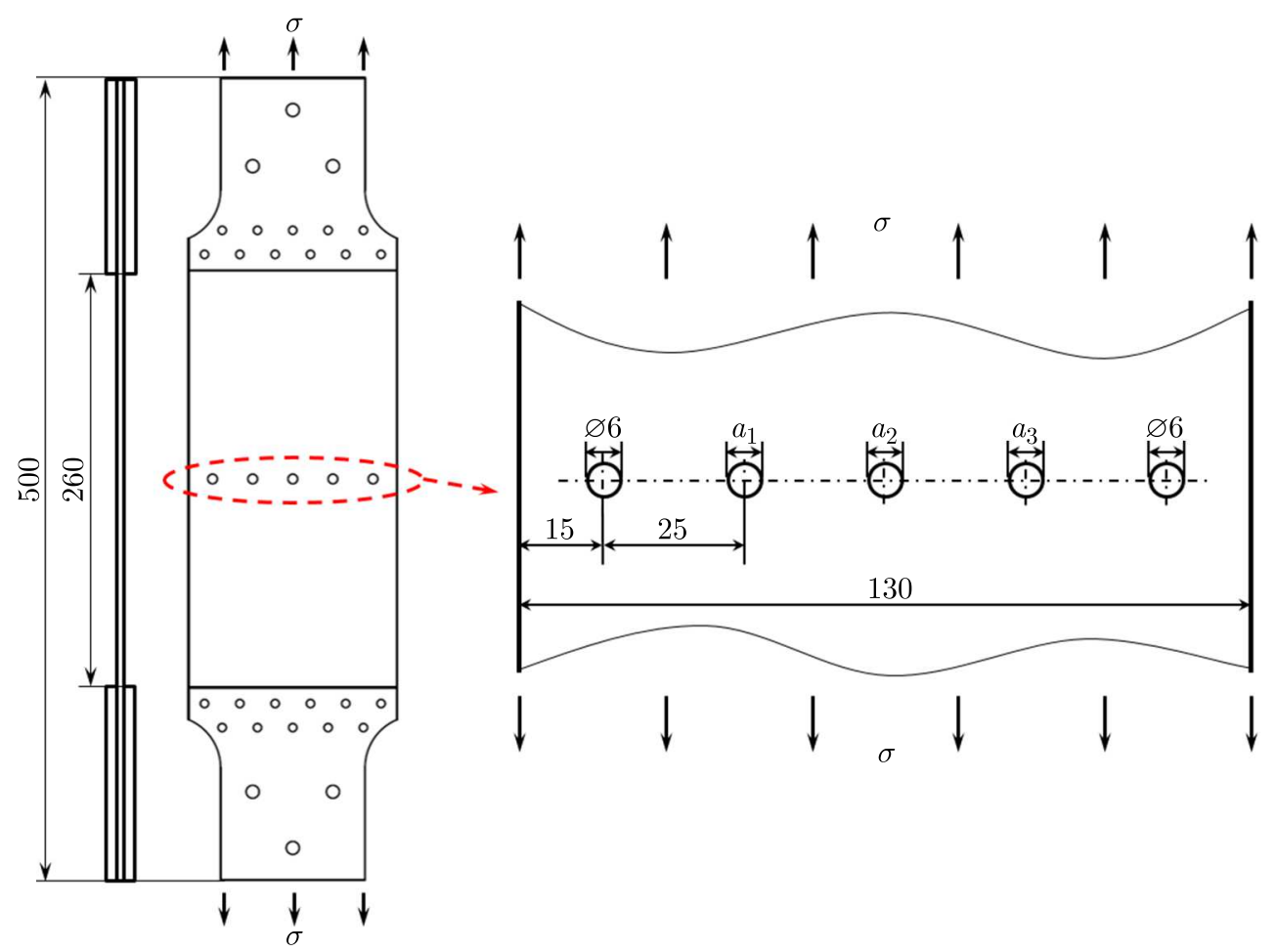

Fig. 5. Configuration of the MSD specimen

Table 6. Specimen parameters and residual strengths of 3 prediction models and MSD tension tests

\begin{tabular}{|c|c|c|c|c|c|c|c|c|}
\hline \multirow{2}{*}{$\begin{array}{c}\text { Speci- } \\
\text { mens } \\
\text { No. }\end{array}$} & \multicolumn{3}{|c|}{ Hole size } & \multirow{2}{*}{$\begin{array}{c}\text { Relative } \\
\text { crack length } \\
2 a / W \\
\end{array}$} & \multicolumn{3}{|c|}{ Prediction models } & \multirow{2}{*}{$\begin{array}{c}\text { Test } \\
{[\mathrm{MPa}]}\end{array}$} \\
\hline & $\begin{array}{c}a_{1} \\
{[\mathrm{~mm}]}\end{array}$ & $\begin{array}{c}a_{2} \\
{[\mathrm{~mm}]}\end{array}$ & $\begin{array}{c}a_{3} \\
{[\mathrm{~mm}]}\end{array}$ & & $\begin{array}{c}\sigma_{N} \\
{[\mathrm{MPa}]}\end{array}$ & $\begin{array}{c}\sigma_{K} \\
{[\mathrm{MPa}]}\end{array}$ & $\begin{array}{c}\sigma_{\xi} \\
{[\mathrm{MPa}]}\end{array}$ & \\
\hline 1 & - & 61.04 & - & 0.94 & 139.4 & 182.2 & 140.8 & 164.3 \\
\hline 2 & - & 60.37 & - & 0.93 & 141.0 & 183.1 & 142.6 & 160.1 \\
\hline 3 & 8.38 & 13.73 & 8.38 & 0.21 & 214.2 & 405.5 & 244.2 & 263.3 \\
\hline 4 & 8.16 & 13.44 & 8.96 & 0.21 & 214.0 & 411.4 & 244.3 & 258.9 \\
\hline 5 & 9.00 & 12.92 & 7.97 & 0.20 & 215.6 & 415.4 & 246.8 & 247.3 \\
\hline 6 & 9.37 & 15.86 & 10.34 & 0.24 & 201.7 & 367.8 & 227.8 & 238.1 \\
\hline 7 & 10.38 & 16.63 & 7.59 & 0.26 & 204.1 & 362.7 & 229.8 & 243.4 \\
\hline 8 & 9.80 & 21.00 & 8.54 & 0.32 & 192.5 & 322.2 & 213.2 & 218.0 \\
\hline 9 & 12.01 & 17.61 & 9.20 & 0.27 & 193.8 & 343.0 & 217.3 & 226.4 \\
\hline 10 & 10.37 & 18.1 & 9.94 & 0.28 & 194.8 & 346.6 & 218.0 & 223.8 \\
\hline 11 & 44.81 & - & 15.11 & 0.69 & 142.1 & 198.63 & 147.9 & 149.7 \\
\hline 12 & 11.4 & 22.63 & 11.58 & 0.35 & 177.1 & 258.9 & 195.1 & 205.2 \\
\hline 13 & 11.12 & 23.52 & 10.82 & 0.36 & 177.5 & 282.7 & 195.0 & 197.9 \\
\hline 14 & 10.23 & 41.52 & - & 0.64 & 162.1 & 211.3 & 169.9 & 202.4 \\
\hline 15 & 9.37 & 26.03 & 11.79 & 0.40 & 173.3 & 246.7 & 188.8 & 206.2 \\
\hline
\end{tabular}

However, the deviation is relative large when the relative crack is short. The net section yield criterion predicts failure based on the amount of the material available to carry the load (Cherry et al., 1997). It is simple and gives relatively reliable predicted values. The $K$-apparent criterion always oversestimates the residual strength of plates. Its predicted results show a big difference with the test results, particularly with lower relative crack length. The DDF model always gives 
acceptable predicted results with various damage degrees. It could be observed from Table 7 that the average error of the DDF model is $6.7 \%$, far less than that of the other two models. In addition, Fig. $6 \mathrm{~b}$ also illustrates the agreement between the DDF model and the test results. Comparing with the approach of Duong et al. (2001) (error -10\%-10\%), the prediction of DDF model is conservative (error $-16.1 \%-0 \%$ ). Thus, the DDF model is moderate and the most accurate among these models.

(a)

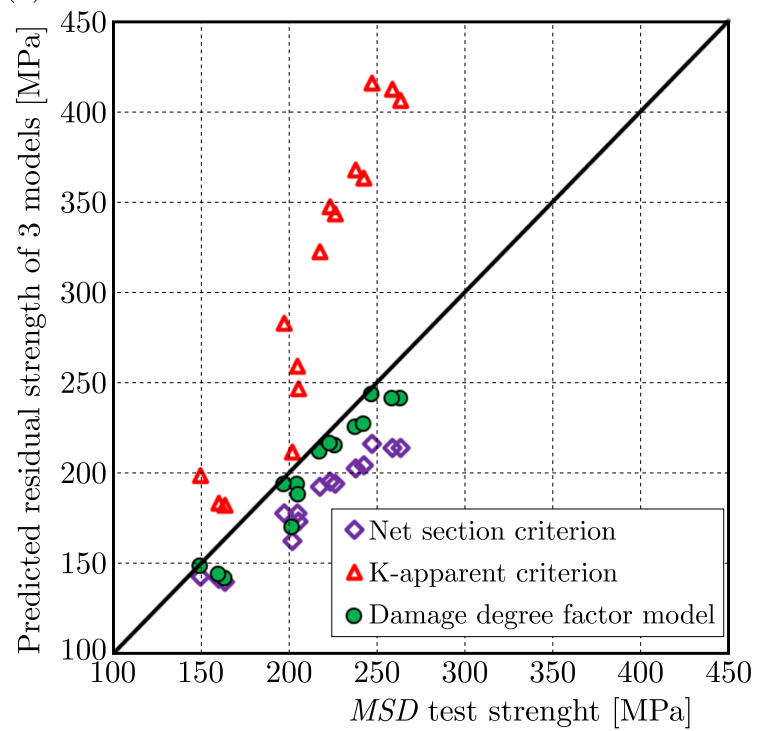

(b)

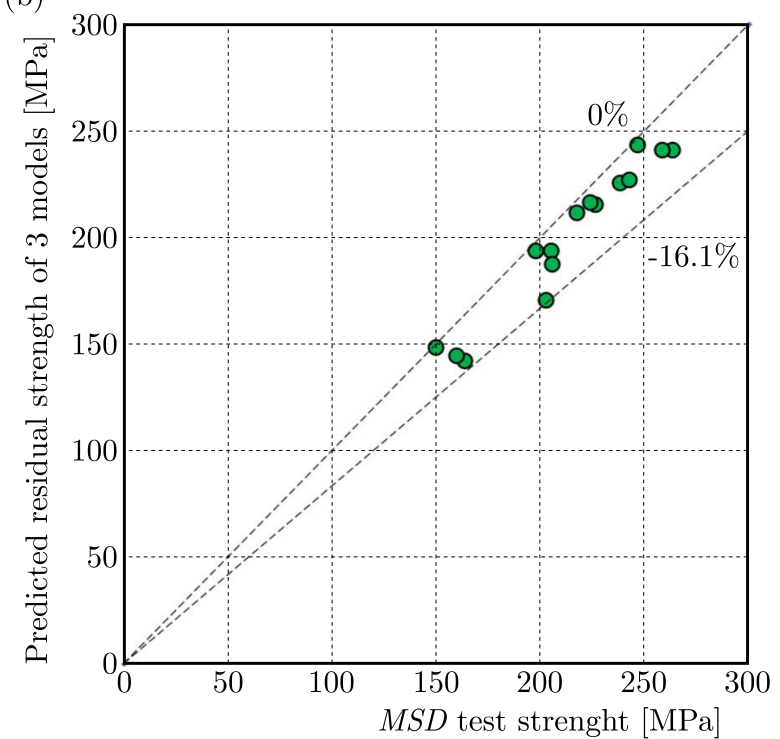

Fig. 6. (a) Empirical analysis results compared to other models of MSD tension tests, (b) Predictions of DDF model vs. test results of MSD tension tests

Table 7. Maximum error and average error between prediction models and MSD tension test results

\begin{tabular}{|l|c|c|}
\hline \multicolumn{1}{|c|}{ Prediction model } & Maximum error [\%] & Average error [\%] \\
\hline \hline Net section yield criterion & -19.9 & 14.1 \\
\hline$K$-apparent criterion & +68 & 39.3 \\
\hline DDF model & -16.1 & 6.7 \\
\hline
\end{tabular}

Thus far, the preliminary results have demonstrated the feasibility and accuracy of the DDF model in predicting the residual strength for flat plates with different damage degrees (i.e. intact, with a single middle crack or with MSD).

\section{Conclusions}

In this investigation, the DDF model is proposed to predict the residual strength of aluminum plates over a wide range of damage degrees. To validate the model, middle crack tension tests on aluminum alloy LY12-CZ and MSD tension tests on aluminum alloy LY2524-T3 are conducted. Comparing with the prediction results of the net section yield criterion and $K$-apparent criterion, DDF model shows a better agreement with the test results, i.e. results of intact plates (error $3.3 \%$ ), results of plates with the middle crack (error within $3.3 \%$ and average error 1.6\%) and results of MSD plates (error $-16.1 \%-0 \%$ and average error $6.7 \%$ ). And compared with the methods of Duong et al. (2001) and Guz and Dyshel (2004), the DDF model is easier to apply. 


\section{Acknowledgement}

The authors would like to express sincere thanks to Mr. Xiangjiong Fu and Professor Qiqing Huang in Northwestern Polytechnical University for their valuable opinions on this work. This research work was supported by the National Natural Science Foundation of China (No. 11372255 and No. 11572261).

\section{References}

1. Broberg K.B., 1971, Crack-growth criteria and non-linear fracture mechanics, Journal of the Mechanics and Physics of Solids, 19, 6, 407-418

2. Broek D., 2012, Elementary Engineering Fracture Mechanics, Springer Science \& Business Media

3. Budynas R.G., Nisbett J.K., 2008, Shigley's Mechanical Engineering Design, New York, McGraw-Hill

4. Cherry M.C., Mall S., Heinimann B., Grandt A.F. JR., 1997, Residual strength of unstiffened aluminum panels with multiple site damage, Engineering Fracture Mechanics, 57, 6, 701-713

5. Cotterell B., Reddel J.K., 1977, The essential work of plane stress ductile fracture, International Journal of Fracture, 13, 3, 267-277

6. Duong C.N., Chen C.C., Yu J., 2001, An energy approach to the link-up of multiple cracks in thin aluminum alloy sheets, Theoretical and Applied Fracture Mechanics, 35, 2, 111-127

7. FAn Z., Li Y., WAng Y., ET AL., 2015, Study on fracture toughness and residual strength of aluminum alloy thin sheet with crack (in Chinese), Advances in Aeronautical Science and Engineering, 6, 1, 52-58

8. Feddersen C.E., 1971, Evaluation and prediction of the residual strength of center cracked tension panels, Damage Tolerance in Aircraft Structures, ASTM International, 50-78

9. Griffith A.A., 1921, The phenomena of rupture and flow in solids, Philosophical Transactions of the Royal Society of London A, 221, 582-593, 163-198

10. Guz A.N., Dyshel M.S., 2004, Stability and residual strength of panels with straight and curved cracks, Theoretical and Applied Fracture Mechanics, 41, 1-3, 95-101

11. Irwin G.R., 1948, Fracture Dynamics, Fracturing of Metals, ASM, Cleveland, 147-166

12. IRWIN G.R., 1957, Analysis of stresses and strains near end of a crack transversing a plate, Journal of Applied Mechanics, 24, 109-114

13. IRwin G.R., 1960, Plastic zone near a crack tip and fracture toughness, Sagamore Ordnance Material Conference, 4

14. JeOng D.Y., Brewer J.C., 1995, On the linkup of multiple cracks, Engineering Fracture Mechanics, 51, 2, 233-238

15. Kachanov L.M., 1958, Time of the rupture process under creep conditions, Izvestiia Akademii Nauk SSSR, Otdelenie Teckhnicheskikh Nauk, 8, 26-31

16. KIRsch U., 1989, Optimal topologies of truss structures, Computer Methods in Applied Mechanics and Engineering, 72, 1, 15-28

17. Lemaitre J., 1985, A continuous damage mechanics model for ductile fracture, Journal of Engineering Materials and Technology, 107, 1, 83-89

18. Li W., Siegmund T., 2002, An analysis of crack growth in thin-sheet metal via a cohesive zone model, Engineering Fracture Mechanics, 69, 18, 2073-2093

19. Li Y., Huang Q., Fu X., Zheng M., 2003, Methodology for residual strength evaluation of cracked structures (in Chinese), Journal of Mechanical Strength, 25, 1, 71-75

20. Liu M., Gan Y., Hanaor D.A.H., Liu B., 2015, An improved semi-analytical solution for stress at round-tip notches, Engineering Fracture Mechanics, 149, 134-143 
21. MCClintock F.A., IRWIN G.R., 1965, Plasticity aspects of fracture mechanics, fracture toughness testing and its applications, ASTM International, DOI: 10.1520/STP26586S

22. Moukawsher E.J., Heinimann M.B., Brandt A.F., 1996, Residual strength of panels with multiple site damage, Journal of Aircraft, 33, 5, 1014-1021

23. Newman J.C., Dawicke D.S., Sutton M.A., Bigelow C.A., 1993, A fracture criterion for widespread cracking in thin-sheet aluminum alloys, ICAF 1\%, International Committee on Aeronautical Fatigue, 443-468

24. PARis P.C., Sin G.C., 1965, Stress analysis of cracks, fracture toughness testing and its applications, ASTM Special Technical Publication, $\mathbf{3 8 1}$

25. RidDick H.K., 1984, Safe-Life and Damage-Tolerant Design Approach for Helicopter Structures Applied Technology Laboratory, US Army Research and Technology Laboratories (AVRADCOM), Virginia

26. Scheider I., Brocks W., 2009, Residual strength prediction of a complex structure using crack extension analyses, Engineering Fracture Mechanics, 76, 1, 149-163

27. Swift T., 1993, Widespread fatigue damage monitoring: Issues and concerns, 5th International Conference on Structural Airworthiness of New and Aging Aircraft

28. Wang L., Brust F.W., Atluri S.N., 1996, Predictions of stable growth of a lead crack and multiple-site damage using elastic-plastic finite element method (EPFEM) and elastic-plastic finite element alternating method (EPFEAM), FAA-NASA Symposium on the Continued Airworthiness of Aircraft Structures, Atlanta, GA, Proceedings, 2, 505-517

29. Yablonskit I.S., 1980, Fracture toughness of sheet materials under static loading, Strength of Materials, 12, 11, 1373-1379

30. Young R.D., Rouse M., Ambur D.R., Starnes J.H. JR., 1998, Residual strength pressure tests and nonlinear analyses of stringer-and frame-stiffened aluminum fuselage panels with longitudinal cracks, The 2nd Joint NASA/FAA/DoD Conference on Aging Aircraft, Williamsburg, VA

31. Zerbst U., Heinimann M., Dalle Donne C., Steglich D., 2009, Fracture and damage mechanics modelling of thin-walled structures - An overview, Engineering Fracture Mechanics, 76, 1, $5-43$

32. ZHU X.K., 2011, Advances in development of J-integral experimental estimation, esting and standardization, ASME 2011 Pressure Vessels and Piping Conference, American Society of Mechanical Engineers, 1239-1246

33. Zhu X.K., Joyce J.A., 2012, Review of fracture toughness (G, K, J, CTOD, CTOA) testing and standardization, Engineering Fracture Mechanics, 85, 1-46 